\title{
CONCEPÇÕES MATEMÁTICAS DE PROFESSORAS DE EDUCAÇÃO INFANTIL
}

\section{MATHEMATICS IN THE CONCEPTIONS OF EARLY CHILDREN'S EDUCATION TEACHERS}

\author{
Janice Anacleto Pereira dos Reis ${ }^{1}$
}

\begin{abstract}
RESUMO
A linguagem matemática é elemento que constitui os mais diversos eventos da vida dos sujeitos. No contexto da Educação Infantil, deve ser compreendida como atividade do pensamento humano, conectada ao contexto social e cultural dos sujeitos e não como disciplina. Sendo assim, as propostas pedagógicas, articuladas às diversas linguagens, devem buscar desenvolver o raciocínio lógico da criança e não a habilidade dela de calcular mecanicamente números ou reconhecer formas geométricas. Desse modo, os docentes podem promover atividades que busquem com que a criança, explore espaços; manuseie e descreva objetos, animais e figuras; formule e registre hipóteses; proponha soluções para diferentes problemas; narre e represente corporalmente fatos, entre outras ações. Este estudo é recorte de uma pesquisa de mestrado do Programa de Pós Graduação/PPGEd em Educação da Universidade Federal de Campina Grande/UFCG, cujo objeto é o brincar na educação infantil. Para essa discussão, refletimos sobre as concepções de professoras de creche e pré-escola de Lagoa Seca-PB, no âmbito da Matemática. Trata-se de uma pesquisa qualitativa, cujos procedimentos utilizados foram a observação que tomamos nota no diário de campo e a entrevista semiestruturada com professoras. Para análise da produção dos dados, nos valemos do método Núcleos de Significação. A Pesquisa aponta práticas pedagógicas com a linguagem matemática, descoladas do contexto cultural e social das crianças, bem como dos interesses delas. O brincar revelou-se modo para auxiliar o aprendizado das crianças de noções matemáticas de adição e subtração, bem como para o reconhecimento de números e figuras geométricas, a partir de propostas que nos pareceram tentativa de prepará-las para o Ensino Fundamental.
\end{abstract}

Palavras-chave: Educação Infantil; Matemática; Prática Pedagógica; Crianças.

\begin{abstract}
Mathematical language is an element that forms the most diverse events in the life of individuals. In the context of Early Childhood Education, it should be understood as an activity of the human thought, linked to the social and cultural contexts of the individuals and not as a course subject. Therefore the pedagogical approaches, linked to several languages, should seek to develop the child's logical thinking and not their ability to mechanically calculate numbers or recognize geometrical shapes. The teacher can promote tasks that make children explore spaces, handle and
\end{abstract}

${ }^{1}$ Mestre em Educação pelo Programa de Pós Graduação em Educação da Universidade Federal de Campina Grande/UFCG, Paraíba-PB, Brasil. Professora Substituta na Unidade Acadêmica de Educação InfantilUAEI/UFCG. Endereço para correspondência: Rua da União, centro, Lagoa Seca, Paraíba-PB, 58117000 E-mail: janiceanacletols@gmail.com

(iD) ORCID: https://orcid.org/0000-0002-6170-3717 
describe objects, animals, and figures, formulate and record hypothesis, come up with solutions for different problems, narrate and bodily represent facts, amongst other actions. This work is an excerpt from a master's research from the Graduate Program in Education at the Federal University of Campina Grande/PB - Brazil, whose object is the act of playing in early childhood education. For this discussion, we reflect upon the pedagogical conceptions of kindergarten and preschool teachers from Lagoa Seca-PB on the scope of Mathematics. It is a qualitative research, whose procedures are the observation and the semi-structured interview. As instruments, we employ the field journal, the microfilming and photographs. The method of analysis applied was Nuclei of Signification. The research points out pedagogical practices with mathematical language, detached from the cultural and social context, as well as from the interests of children. Playing proved to be a way to help children's learning of mathematical operations of addition and subtraction, as well as the recognition of numbers and geometric shapes, based on proposals that seemed to us an attempt to prepare them for Elementary School.

Keywords: Early Childhood Education; Mathematics; Pedagogical Practice; Children. 


\section{Introdução}

Segundo Panizza (2006) em 1970 emergiu a escola francesa de didática da Matemática, com a preocupação de refletir sobre os processos de aquisição e construção do conhecimento matemático. A partir dessa perspectiva, compreendemos a Matemática como conhecimento que deve buscar ser construído a partir das vivências dos sujeitos.

$\mathrm{Na}$ etapa da Educação Infantil ${ }^{2}$, a Matemática é compreendida como uma linguagem importante para o desenvolvimento e aprendizado da criança, pela a qual ela se expressa, interage com o mundo e produz cultura. Nesta direção, as práticas com os sujeitos de 0 a 5 anos de idade devem ser norteadas pelos eixos as interações e a brincadeira, a partir de vivências que contemplem relações quantitativas, medidas, sequência, ordem, orientações-espacial, situações temporais, entre outras (BRASIL, 2009; SMOLE, IGNEZ; CÂNDIDO, 2000; RANIERI; GOMES; MONTENEGRO, 2013).

Ao registrar situações do cotidiano, a exemplo, de criar uma lista de convidados para a apresentação de dança que ocorrerá na escola, a criança está lidando, de modo brincante, com situações reais que envolvem as noções matemáticas, como: elaborar um convite de acordo com a quantidade de convidados (as); pensar sobre altura e medidas do convite; planejar data e horário para o evento; organizar o espaço físico da apresentação (posição do palco e cadeiras, tamanhos e espessuras das cortinas, entre outros). Estas e outras questões envolvem diretamente o fazer pedagógico da educação infantil com as noções matemáticas.

Esse artigo, recorte de uma pesquisa de mestrado, realizada pelo Programa de Pós Graduação em Educação - PPGEd, da Universidade Federal de Campina Grande - UFCG, entre os anos de 2017 a 2019, reflete sobre o brincar na educação infantil. A pesquisa teve como objeto de estudo o brincar na educação infantil. Para essa discussão, refletimos sobre as concepções de seis professoras de duas creches ${ }^{3}$ do município de Lagoa SecaPB no contexto da Matemática.

Na pesquisa, utilizamos a abordagem qualitativa interpretativista, uma vez que a produção dos dados se deu a partir dos significados humanos sobre um dado fenômeno

\footnotetext{
${ }^{2}$ Educação Infantil com iniciais em maiúsculas refere-se à primeira etapa da educação básica. $\mathrm{O}$ termo educação infantil com iniciais em minúsculas à educação dos sujeitos de 0 a 5 anos de idade.

${ }^{3}$ Uma creche pesquisada localiza-se na zona urbana e a outra na zona rural de Lagoa Seca-PB.
} 
(GIL, 2008) e, neste caso, sobre as concepções das professoras pesquisadas sobre a matemática na educação infantil.

Por procedimentos, utilizamos observações por permitirem que os eventos pudessem ser percebidos diretamente pelo pesquisador (GIL, 2008). Observamos cinco grupos de educação infantil.

Na creche localizada na zona urbana, observamos o grupo 1 (crianças de três anos de idade) com a professora A no turno da manhã e a tarde com a professora B; o grupo 2 (crianças de quatro anos de idade) com a professora C; grupo 3 (crianças de cinco anos de idade) com a professora D. Na creche da zona rural, pesquisamos o grupo 4 (crianças de dois anos de idade) com a professora E e o grupo 5 (crianças de três anos de idade) com a professora F. Cada grupo foi contemplado com quatro observações.

Utilizamos ainda, a entrevista semiestruturada com as professoras pesquisadas, por corresponder a um esquema flexível capaz de possibilitar a realização de necessárias adaptações durante as entrevistas (LÜDKE; ANDRÉ, 1986).

Para documentar as observações e entrevistas utilizamos o diário de campo, as fotografias, as filmagens e gravações em áudio para registramos nossas idas à campo, os acordos, impressões, entre outros episódios importantes na pesquisa. As fotografias e as filmagens nos proporcionaram registrar eventos que chamaram nossa atenção, envolvendo as professoras e a crianças na relação com o brincar (PINHEIRO; KAKEHASH; ANGELO, 2005). As gravações em áudio foram utilizadas durante as entrevistas com as professoras como modo de nos auxiliar a documentar momentos que transcendem anotações (CRUZ NETO, 1994).

Para análise dos dados, nos valemos do método Núcleos de Significação, que objetiva aos pesquisadores apreender o processo de constituição das significações construídas pelos sujeitos. As etapas desse método se dividem em: a) Levantamento dos pré-indicadores; b) Sistematização dos indicadores e c) Construção dos núcleos de significação. A primeira etapa consiste nas informações apreendidas no campo de pesquisa referente às observações e entrevistas. A segunda etapa é a aproximação dos sentidos constituídos pelos sujeitos no diário de campo, nas entrevistas transcritas, gravações em áudio e filmagens. A última etapa é a constituição dos núcleos de significação que é a síntese das categorias construídas, a partir das etapas anteriores (AGUIAR; SOARES, 2006; AGUIAR; SOARES; MACHADO, 2015). 
A partir dos dados produzidos, na pesquisa, construimos as seguintes categorias: a) A rotina das crianças na creche: tempo e espaço; b) A escolarização do brincar: as crianças e as brincadeiras; c) Brincadeiras livres: vivências culturais das crianças e; d) $\mathrm{O}$ brincar entre o natural e o social. A partir dessas categorias, apresentamos concepções de professoras de educação infantil sobre a Matemática em grupos de creche e pré-escola ${ }^{4}$.

\section{A Matemática na Educação Infantil}

Como dito anteriormente, a década de 1970 foi crucial para que discussões da escola francesa, a respeito da didática da Matemática, como elemento de conhecimento concreto, pudessem ascender como algo que permeia a vidas das pessoas. Nesse sentido, a didática da Matemática busca auxiliar alunos/as e crianças ${ }^{5}$ a construírem um conhecimento que possibilitem à reflexão e resolução de problemas, a partir do contexto cultural e social (PANIZZA, 2006).

Nessa perspectiva, discussões emergiram no mundo, em torno da reflexão de práticas pedagógicas que considerem a construção do conhecimento matemático, a partir de conhecimentos prévios dos sujeitos. O papel do professor/a é mediar à relação entre o que o aluno (a) /criança já sabe com o que busca saber.

No contexto brasileiro, foi somente com a redemocratização do país, com a promulgação da Constituição Federal (BRASIL, 1988) que a escola passou a ser vista como espaço democrático, cujas práticas devem ser contextualizadas. Nesta direção, a Educação Infantil emerge como primeira etapa da educação básica, ofertada em espaços de creche e pré-escola, cujo objetivo é cuidar e educar dos sujeitos, a partir de propostas norteadas pelos eixos as interações e a brincadeira (BRASIL, 1996, 2009).

No âmbito da Matemática na educação infantil, importante que esta seja conectada, ainda, as demais áreas de conhecimento, tais como: Geografia, História, Artes, Língua Portuguesa, Literatura, entre outras.

Mais que uma área de conhecimento a Matemática é uma linguagem. Nesse sentido, Smole (2000) considera a aprendizagem da Matemática aquisição e domínio de uma nova linguagem pela criança, pois atravessa a vida desde o nascimento, exercendo

\footnotetext{
${ }^{4}$ Creche- 0 a 2 anos de idade. Pré-escola, crianças de 4 a 5 anos de idade (BRASIL, 2017).

${ }^{5}$ Designa-se o uso do termo criança para se referir aos sujeitos da Educação Infantil (BRASIL, 2009). Os termos aluno e aluna são empregados para os sujeitos das demais modalidades da educação básica.
} 
função sociocomunicativa. Quando um bebê, por exemplo, deseja pegar um chocalho, intuitivamente, calcula a distância entre ele o objeto, poderá estender o braço, apontandoo para algum adulto que estiver por perto. Ao torna-se adulto, essas questões ampliam-se nas situações do cotidiano. A hora e distância para irmos até dados lugares; o tempo que o alimento deve ser cozido e temperatura adequada; no volume líquido de café que colocamos em uma xícara; na quantidade de ingredientes para a receita de um bolo; no dinheiro de troco que recebemos na padaria, entre outras.

Na educação infantil, um projeto pedagógico interessante para a criança permite a intercomunicação entre a Matemática e as diversas áreas de conhecimento humano. Ao construir um barquinho de papel, por exemplo, a criança, ao mesmo tempo em que vivencia conhecimentos matemáticos como verificar a medida do papel, ela ainda acessa outros, tais: figura geométrica, desenho, pintura, escrita, entre outros que poderão ajudála a dialogar e comunicar ideias divergentes, aspectos estes, importantes para o desenvolvimento infantil (EDWARDS; GANDINI; FORMAN, 1999; SMOLE, 2000).

Desta maneira, a criança poderá fazer Matemática ao invés de reproduzi-la, tornando-se capaz de formular e resolver por si, questões matemáticas, através da possibilidade de questionar e levantar hipóteses, adquirindo e aplicando-as em situações da vida prática (SMOLE, 2000; SMOLE, IGNEZ; CÂNDIDO, 2000; RANIERI; GOMES; MONTENEGRO, 2013).

Na Educação Infantil, a Matemática não deve ser vista como disciplina, mas como atividade do pensamento em permanente relação com o cotidiano, nos mais diversos espaços sociais. Desse modo, é crucial que desde cedo, a criança seja encorajada a desenvolver e ampliar seu raciocínio lógico, a partir de princípios que envolvam relações quantitativas, de medida, orientações-espacial, sequência, volume, ordem, situações temporais entre outras (ARANÃO, 2011; BRASIL, 2009, 2017).

A criança ao vivenciar propostas pedagógicas em que deve comparar a quantidade de biscoitos que ganhou em relação ao colega; identificar semelhanças e diferenças entre objetos e alimentos; produzir desenhos, brincar ou ler gibis e histórias infantis, consegue, gradativamente, se apropriar de conhecimentos do universo matemático (ARANÃO, 2011; RANIERE; GOMES; MONTENEGRO, 2013).

A criança deve, portanto, ser incentivada a tentar perceber que a Matemática faz parte da vida e, que, inclusive, a rotina da creche ou escola de educação infantil é 
organizada por esta área de conhecimento. A hora do banho, alimentação e sono, por exemplo, são eventos que ocorrem organizados por uma lógica temporal, de sequência, ordem e localização espacial.

Dessa forma, as práticas na educação infantil devem transcender o ensino descontextualizado de números ou figuras geométricas, buscando articulares os conhecimentos da Matemática com os conhecimentos de mundo da criança. Importante a criança saber que um círculo é uma figura redonda, mas que há ainda, outras figuras semelhantes no seu meio e que não, necessariamente, são redondas (SMOLE, 2000).

A seguir, discorremos, sobre concepções de professoras de educação infantil, evidenciadas em suas respectivas práticas no âmbito da Matemática, a partir da pesquisa.

\section{As noções matemáticas nas práticas de professoras de educação infantil}

Muito embora, o contexto cultural das instituições de educação infantil pesquisadas, se diferenciem, sendo um na zona rural e a outra na zona urbana do município de Lagoa Seca-PB, observamos, práticas semelhantes. No âmbito da Matemática,

As práticas das professoras pesquisadas, tanto da zona rural quanto da zona urbana com a Matemática, pareceram-nos restringir-se ao ensino de números, figuras geométricas e operações de adição e subtração (Diário de Campo, 22/ 03/2019).

Práticas nesta perspectiva não somete limitam o universo da Matemática como ainda, podem revelar certa intenção de preparar a criança da Educação Infantil para o Ensino Fundamental sendo que, o foco da educação para o sujeito de 0 a 5 anos de idade deve estar nas interações, não nos conteúdos, como é comum ocorrer nos anos iniciais do Ensino Fundamental. Nesse sentido, é crucial que o fazer pedagógico no âmbito da Matemática, ultrapasse o reconhecimento de números, figuras geométricas ou aprendizado da criança de operações de adição e subtração, de maneira que outros conceitos como: medida, volume, densidade, cumprimento, tempo, distância, tamanho, entre outros sejam explorados pelo raciocínio lógico da criança.

Nas práticas das professoras pesquisadas, observamos ainda, a valorização dos jogos e brincadeiras como elementos relevantes para o aprendizado da Matemática das crianças dos seus respectivos grupos. 
A professora $\mathrm{F}$ criou um jogo elaborado a partir de rolos de papel higiênico. Nos rolos estão impressos números. Cada rolo representa um peixe que está em um aquário (uma bacia). As crianças, individualmente, com uma vara de pescar (brinquedo de plástico), simulam pescar os peixinhos (rolos de papel higiênico) e devem relatar para a professora o número impresso nele (Diário de Campo, 28/03/2019).

Importante que as práticas nas instituições de educação infantil sejam baseadas pelo brincar, uma vez que é a principal atividade da criança, bem como um direito que, a ela, deve ser garantido (KISHIMOTO, 2011). No relato em diário de campo, a questão é a maneira como as crianças são convidadas pela professora a vivenciar a proposta, aparentemente, somente para o reconhecimento de números.

$\mathrm{Na}$ Educação Infantil, as propostas envolvendo a Matemática devem ser originadas, a partir de alguma situação problema emergente no grupo. Nessa condição, a criança poderá exercer a condição de sujeito ativo e protagonista na produção de conhecimento, não receptora de propostas prontas.

A professora E, do grupo 4, levou para as crianças um jogo de boliche, criado a partir de garrafas PET. As garrafas eram coloridas, com números. Cada criança deveria derrubar as garrafas com uma bolinha pequena de plástico e, em seguida, discorrer para a professora as cores e números que reconheciam (Diário de Campo, 25/03/2019).

O jogo é crucial para o desenvolvimento e aprendizado infantil, uma vez que envolve as diversas áreas de conhecimento. Jogando sozinha ou com a intervenção do adulto, a criança se socializa, aprende regras de convivência, rotinas, culturas e cerimônias institucionais nos espaços coletivos onde estão sujeitas (CORSINO, 2009). No contexto da Matemática, destacamos que as propostas envolvendo jogos devem ser questionadas antes de levadas à criança: Quais objetivos? Permitem a criança se colocar como sujeito? Exploram as diversas noções matemáticas? Compreensões como estas podem ampliar a visão de mundo da criança como algo interessante, a ser constantemente descoberto.

No grupo 4, Paloma (nome fictício) em um momento de solitude, aprecia sua própria companhia, em uma brincadeira no velocípede. Ao se entediar com o brinquedo, vai à estante e pega algumas peças de encaixe, as quais se transformam em um bolo de aniversário, acompanhado pela música de parabéns. Levantando as mãos para cima canta: "Parabéns para você, dessa data querida...”. Antes de concluir a música, percebe a presença de um colega 
que vai passando e coloca em sua boca uma peça de encaixe: "Toma teu gagau !” (Diário de Campo, 22/03/2019).

Paloma, criança de 2 anos de idade, parece já referenciar algumas noções matemáticas. Na brincadeira, ela revela aspectos do raciocínio lógico, como: ir à estante e pegar um brinquedo e colocar uma peça de encaixe na boca de um colega, mediante localização espacial. Nesse sentido, observamos que a Matemática se apresenta nas mais diversas situações do cotidiano dos sujeitos das mais variadas faixas etárias.

Diante disso, a escola de educação infantil deve proporcionar às crianças, por meio de brincadeiras, dramatizações, histórias, entre outras vivências, propostas que abordem o conhecimento matemático.

Tem um joguinho que é de encaixe, que é para botar as formas geométricas dentro do triângulo, aí você pega aquele jogo e bota a criança para brincar sem nenhum objetivo [...] quando a criança se torna um adulto, às vezes vai guardar um objeto dentro de um móvel, um objeto enorme e quer empurrar dentro do armário e, não cabe, é porque não foi trabalhada a coordenação motora (Entrevista professora A, 20/03/2019).

Dois aspectos, claramente, se sobressaem na fala da professora: as figuras geométricas e o jogo na educação infantil. A manipulação da criança das formas geométricas, por meio de jogos é interessante, tendo em vista o trabalho de investigar, classificar e comparar da criança em torno dos objetos. Muito embora, a professora afirme não estabelecer objetivos para essas situações, ela aponta que o jogo contribui para o desenvolvimento da coordenação motora infantil, ao exemplificar a compatibilidade entre um dado objeto e o espaço físico de um armário. Segundo a professora, há adultos que não conseguem realizar essa distinção, reflexo, de uma coordenação motora não potencializada na educação infantil. Com isso, ela esboça intencionalidade, em torno da criança, como um sujeito que deverá ser educado para alguém que virá a ser algo no futuro e não como alguém que já está sendo, que vive e possui necessidades no tempo presente.

\section{Considerações Finais}

A Matemática organiza a vida desde os primórdios da humanidade. Sabemos que os primeiros povos tinham o hábito de registrar em pedras e cavernas eventos cotidianos, a exemplo, da caça, pesca, condições de tempo, entre outros. Com o passar do tempo, esses registros foram se aperfeiçoando e, daí, o surgimento de noções matemáticas, tais 
como: número, quantidade, sequência, seriação, álgebra, função, espaço (ARANÃO, 2011).

A Educação Infantil enquanto primeira etapa da educação básica que visa o desenvolvimento integral da criança (BRASIL, 2009) deve contemplar práticas no âmbito da Matemática que, envolvam relações e eventos do cotidiano da criança, buscando o desenvolvimento da capacidade de dedução do raciocínio lógico e não de habilidades meramente mecânicas, mediante conceitos abstratos e descolados da realidade cultural e social dos sujeitos (CARVALHO, 2004; SMOLE, IGNEZ; CÂNDIDO, 2000).

Para melhor possibilitar à criança práticas de qualidade no contexto das noções matemáticas, importante sabermos a respeito das especificidades dos sujeitos de 0 a 2 anos de idade e 4 a 5 anos de idade. A fase de 0 e 2 anos de idade é marcada por reflexos, sucção e comportamentos instintivos, cujo corpo é a principal forma de comunicação. Dos 4 a 5 anos de idade, ocorre a maturação dos esquemas mentais da criança, expandindo sua interação com o meio físico que a rodeia (REGO, 2014).

Diante disso, a criança de 0 a 2 deve vivenciar propostas que a possibilite explorar objetos, encaixar, juntar, soltar, equilibrar, jogar, cantar, rodar, engatinhar, entre outras. Com a criança de 4 a 5 além dessas possibilidades, esta, deve ser estimulada, a descrever objetos, animais, figuras; formular e registrar hipóteses; propor soluções para diferentes problemas; decidir e ordenar ações; narrar fatos (ARANÃO, 2011; MORENO, 2006).

Na pesquisa, observamos que o trabalho pedagógico com as noções matemáticas pouco contempla as especificidades de desenvolvimento entre as faixas etárias. Ou seja, percebemos práticas semelhantes entre as crianças 2 a 3 e 4 a 5 anos de idade. Com isso, as professoras, pareceram desconhecer as questões de desenvolvimento entre as faixas etárias, de maneira que as propostas piorizavam o aprendizado de noções de operações de adição e subtração, bem como o reconhecimento de números e figuras geométricas, como triângulo, círculo e quadrado. Jogos e brincadeiras foram percebidos como elementos valorizados pelas professoras nesse processo.

A questão é o modo como às práticas se davam, desconectadas do contexto social e cultural das crianças, pouco considerando elas como sujeito protagonista no seu processo de desenvolvimento e aprendizagem. Ademais, evidenciamos tímido conhecimento das professoras sobre os aspectos que norteiam a Educação Infantil, como o brincar enquanto eixo que deve nortear as propostas pedagógicas. 
Na educação infantil, crucial que as propostas com a Matemática tenham conexão com áreas de conhecimento, tais como: Geografia, História, Língua Portuguesa, Artes Plásticas, entre outras, uma vez que o desenvolvimento da criança não é somente cognitivo é, ainda, afetivo, psicológico, cultural, social, físico e intelectual (BRASIL, 2009). Portanto, as propostas devem ser pensadas para que a criança interaja integralmente com o meio e com outros sujeitos e, não para que vivencie situações pontuais como aprendizado de números ou figuras geométricas.

\section{Referências}

AGUIAR, Wanda Maria Junqueira de; SOARES, Júlio Ribeiro. Núcleos de significação como instrumento para a apreensão da constituição dos sentidos. Psicologia Ciência e Profissão, 2006, 26 (2), 222-245. Disponível em: http://www.scielo.br/pdf/pcp/v26n2/v26n2a06.pdf. Acesso em: 14 dez. 2018.

AGUIAR, Wanda Maria Junqueira de; SOARES, Júlio Ribeiro; MACHADO, Virgínia Campos. Núcleos de significação: uma proposta histórico-dialética de apreensão das significações. Cadernos de Pesquisa, v.45, n.155, p. 56-75, jan./mar.2015. Disponível em: http://www.scielo.br/scielo.php?pid=S010015742015000100056\&script=sci_abstr act . Acesso em: 14 jan.2018.

ARANÃO, Ivana V.D. A matemática através de jogos e brincadeiras. Ilustração Carlos Alexandre. Campinas. $-7^{\text {a }}$ edição. - Campinas, SP: Papirus, 2011.91 p.

BRASIL. Constituição da República Federal do Brasil. Brasília, DF: Presidência da República. 1988. Disponível em:

http://www.planalto.gov.br/ccivil_03/constituicao/constituicaocompilado.htm. Acesso em: 24 ago. 2018.

BRASIL. Lei n. 9.394. Diário Oficial da República Federativa do Brasil. Diretrizes e Bases da Educação Nacional. Brasília, DF: 23 de dezembro de 1996, p. 27.833. Disponível em:

http://portal.mec.gov.br/index.php?option=com_docman\&view=download\&alias=9769diretrizescurriculares-2012\&category_slug=janeiro-2012-pdf \&Itemid=30192. Acesso em: 23 ago.18.

BRASIL, Resolução no 5 de 17 de dezembro de 2009. Diretrizes Curriculares Nacionais para a Educação Infantil. Ministério da Educação. Secretaria de Educação Básica. - Brasília: MEC, SEB, 2009. Disponível em:http://portal.mec.gov.br/index.php?option=com_docman\&view=download\& alias=9769-diretrizescurriculares-2012\&category_slug=janeiro-2012pdf\&Itemid=30192. Acesso em: 08 ago. 2017. 
BRASIL, Resolução CNE/CP No 2, de 22 de dezembro 2017. Base Nacional Comum Curricular para a Educação Infantil. Disponível em: http://basenacionalcomum.mec.gov.br/images/historico/RESOLUCAOCNE_CP222DE DEZEMBRODE2017.pdf. Acesso em: 12 ago. 2020.

CARVALHO, Mercedes. Aprender, contar e resolver problemas matemáticos na Educação Infantil. In: Matemática e Educação Infantil: investigações e possibilidades de práticas pedagógicas. Mercedes Carvalho, Marcelo Almeida Bairral (orgs.). $2^{\mathrm{a}}$ edição. - Petrópolis, RJ: Vozes, 2004. 186 p.

CORSINO, Patrícia. Considerações sobre o planejamento na educação infantil. In: Educação Infantil: cotidiano e políticas. Campinas, SP: Autores Associados, 2009. 133 p.

CRUZ NETO, Otávio. O trabalho de campo como descoberta e criação. In: Pesquisa social: teoria, método e criatividade. DESLANDES, Suely Ferreira; CRUZ NETO, Otávio; GOMES, Romeu; MINAYO, Maria Cecília (org.). 23. edição. Petrópolis: Vozes, p. 51-66.1994.

EDWARDS, Caroyn; GANDINI, Lella; FORMAN, George. As cem linguagens da criança. Tradução de Dayse Batista. Porto Alegre: Editora Artes Médicas Sul Ltda, 1999. $319 \mathrm{p}$.

GIL, Antonio Carlos. Métodos e técnicas de pesquisa social. $6^{\text {a }}$ edição. São Paulo: Atlas, 2008. Disponível em: https://ayanrafael.files.wordpress.com/2011/08/gil-a-cmc3a9todos-e-tc3a9cnicas-de-pesquisa-social.pdf. Acesso em: 24 ago. 2018. KISHIMOTO, Tisuko Morchida. O jogo e a educação. In: Jogo, brinquedo, brincadeira e a educação. Tizuko M. Kishimoto (org.). 14 .ed. São Paulo: Cortez, 2011. 207 p.

LÜDKE, Menga; ANDRÉ, Marli E. D. A. de. Abordagens qualitativas de pesquisa: a pesquisa etnográfica e o estudo de caso. In: Pesquisa em educação: abordagens qualitativas. São Paulo: EPU, p. 11-45. 1986.

MORENO, Beatriz, Ressia. O ensino de números e do sistema de numeração na educação infantil e na $1^{a}$ série. In: Ensinar matemática na educação infantil e nas séries iniciais do ensino fundamental: análise e propostas. Mabel Panizza (org). Tradução de Antonio Feltrin.-Porto Alegre:Artmed, 2006. 188 p.

PANIZZA, Mabel. Conceitos básicos da teoria de situações didáticas. In: Ensinar matemática na educação infantil e nas séries iniciais do ensino fundamental: análise e propostas. Mabel Panizza (org). Tradução de Antonio Feltrin.-Porto Alegre:Artmed, 2006. 188 p.

RANIERI, Anna Cláudia; GOMES, Liliane; MONTENEGRO, Priscila. Matemática no dia a dia da educação infantil: rodas, cantos, brincadeiras e histórias. - 2.ed.- São Paulo: Livraria Saraiva, 2013. 192 p. 
REGO, Tereza Cristina. Vygotsky: uma perspectva histórico-cultural da educação. 25. ed.- Petrópolis, RJ:Vozes, 2014. 139 p.

PINHEIRO, Eliana Moreira; KAKEHASH, Tereza Yoshiko; ÂNGELO, Margareth. O uso de filmagem em pesquisas qualitativas. Rev. Latino-americana de Enfermagem 2005. set./out.; 13(5): 717-22. Disponível em:

http://www.scielo.br/pdf/rlae/v13n5/v13n5a16.pdf . Acesso em: 08 ago. 2017.

SMOLE, Kátia Stocco. As inteligências na educação infantil: a teoria das inteligências múltiplas na prática escolar. Porto Alegre: Penso, 2000. 206 p.

SMOLE, Kátia Stocco; IGNEZ; Maria Diniz; CÂNDIDO, Patrícia. Resoluções de problemas: mátemática de 0 a 6.- Porto Alegre: Artes Médicas Sul, 2000. 96 p.

Recebido em: $16 / 02$ / 2021

Aprovado em: 18/04/2021 